Устаев Рустам Мерзеферович, Гюльнезерова Мальвина Нережуллаховна, Тадтаев Дзамболат Мервадикович

\title{
ОБ УПРАВЛЕНИИ ИНФОРМАЦИОННО-ЦИФРОВОЙ СИСТЕМОЙ ОБЕСПЕЧЕНИЯ ЕДИНСТВА ОБРАЗОВАТЕЛЬНОЙ И КАДРОВОЙ ПОЛИТИК ТЕРРИТОРИЙ
}

Статья направлена на решение фундаментальной научной задачи эффективного управления информационно-цифровой системой обеспечения единства образовательной и кадровой политик территорий в контексте развития искусственного интеллекта в экономике Российской Федерации и цифровой экономики в Республике Южная Осетия. Решение данной проблемы позволит обеспечить заметный технолого-экономический рост страны в контексте стратегий на базе искусственного интеллекта в рамках ответа российского обиества на больиие вызовы научно-технологического развития Российской Федерации, а также создать условия для развития международного научно-технологического сотрудничества России и Южной Осетии в формате дигитализации экономики.

Ключевые слова: ицфровая экономика, модернизация, образовательная политика, кадровая политика, человеческий капитал, искусственный интеллект, экономика Российской Федерации, Республика Южная Осетия.

Rustam Ustaev, Mal'vina Gyul'nezerova, Dzambolat Tadtaev ABOUT MANAGEMENT OF INFORMATION AND DIGITAL SYSTEM OF ENSURING UNITY OF EDUCATIONAL AND PERSONNEL POLICIES OF TERRITORIES

The article is aimed at solving the fundamental scientific problem of effective management of information and digital system to ensure the unity of educational and personnel policies of the territories in the context of the development of artificial intelligence in the economy of the Russian Federation and the digital economy in the Republic of South Ossetia. The solution of this problem will provide a significant technological and economic grow th of the country in the context of strategies based on artificial intelligence in the framework of the Russian society's response to the big challenges of scientific and technological development of the Russian Federation, as well as create conditions for the development of international scientific and technological cooperation between Russia and South Ossetia in the format of digitalization of the economy.

Key words: digital economy, modernization, educational policy, personnel policy, human capital, artificial intelligence, economy of the Russian Federation, Republic of South Ossetia.

Bведениe/Introduction. Сегодня важным направлением считается обеспечение существенного технологического и экономического роста России в контексте стратегий на базе искусственного интеллекта. Новая цифровая экономика, или новый мир машин, порождают основные вызовы, последствия, перспективы и ключевые преимущества современных подходов в практике управления субъектами цифровой экономики

Проекты по цифровизации являются приоритетными, так как позволяют придать развитию экономики страны новый позитивный импульс.

В настоящее время российская экономика находится в стадии трансформации и глобальных изменений экономического и технологического укладов. Положение на рынке труда и образовательных услуг России вызывает необходимость изменения содержания образования применительно к современным требованиям. Изменилась роль человека, потому что он стал главным 
ресурсом модернизации [12]. Раскрывается сектор цифровой трансформации: важность баланса стратегии и тактики развития бизнеса и общества, вопросы вовлечения человеческого капитала и общества в управление модернизацией экономики в условиях глобализации. Существует необходимость формирования многокомпонентной информационно-образовательной среды на основе единства образовательной и кадровой политики, которую можно считать частью цифровой экономики [8]

Процесс управления информационно-цифровой системой обеспечения единства образовательной и кадровой политики региона представляет собой систему со сложной структурой, многообразными функциями и непростой диалектикой развития. Создается своего рода «мировое образовательное пространство», которое задает критерии развития и российскому образованию. Информационные и цифровые технологии дают возможность перестраивать наше настоящее, и потому сегодня главная задача - быть готовым к существованию в этих условиях, выстроить совершенно новые коммуникации, а также новые отношения среди людей, к перестройке всей экономики и общества, чтобы наша жизнь была лучше и «умнее».

Таким образом, актуальным является вопрос цифровизации экономики Российской Федерации и партнеров страны. Развитие информационно-цифровых систем управления на основе применения искусственного интеллекта способно значительно повысить эффективность экономических и политических институтов, способствует социальному, научно-технологическому развитию. Интеграционные процессы территорий требуют использования современных технологий и наиболее передовых методов управления для обеспечения единства образовательной и кадровой политик.

Обработка больших объемов данных уже не один год считается одним из перспективных направлений в области информационных технологий искусственного интеллекта. Уверенность непосредственного влияния на глобальную технологическую конкурентоспособность отчетливо описана в Стратегии развития отрасли информационных технологий в Российской Федерации на 2014-2020 годы и на перспективу до 2025 года. Подтверждающие положения о необходимости развития искусственного интеллекта и применения соответствующих технологий содержатся не только в стратегических, но и в отраслевых документах Министерства труда и социальной защиты РФ, Министерства науки и высшего образования РФ, Министерства промышленности и торговли РФ, Министерства транспорта РФ, Министерства здравоохранения РФ

Однако законодательно определение самого понятия «искусственный интеллект» пока отсутствует. Расставить акценты в этом вопросе попытались отечественные и зарубежные ученые $[1,2,5,6]$.

Президент РФ Владимир Путин утвердил национальную стратегию развития искусственного интеллекта на период до 2030 года. Соответствующий указ опубликован на официальном интернет-портале правовой информации 11 октября 2019 г. Предшественником данного указа считается Указ Президента РФ от 09.05.2017 № 203 «О Стратегии развития информационного общества в Российской Федерации на 2017-2030-е гг.».

Президент также поручил Правительству РФ до окончания текущего года разработать федеральный проект «Искусственный интеллект», который будет включен в нацпрограмму «Цифровая экономика». Национальная программа «Цифровая экономика Российской Федерации» утверждена Распоряжением Правительства РФ № 1632-р в 2017 г. и предполагает коррелирующий результат при реализации шести федеральных проектов: «Нормативное регулирование цифровой среды», «Информационная инфраструктура», «Кадры для цифровой экономики», «Информационная безопасность», «Цифровые технологии» и «Цифровое государственное управление» [12].

Стратегия развития искусственного интеллекта активно обсуждается не только в Российской Федерации. Ведущие государства приняли национальные программы.

Позиции лидера в этой области уверенно занимает Китай, который уже вкладывает около $\$ 170$ млрд в год, прогноз на 2025 г. фиксирует превышение этой цифры $\$ 800$ млрд. Для сравнения расходы на ИИ в США около \$26 млрд в год. Внедрение этих технологий обеспечит к 2025 г. удвоение темпов роста ВВП ведущих стран и увеличение мирового ВВП на $\$ 15$ трлн. 
На неоднократное обсуждение вопроса искусственного интеллекта и его роль в развитии цифровой, «умной», экономики было обращено внимание Государственного университета управления, Финансового университета при Правительстве Российской Федерации, Департамента правового регулирования экономической деятельности, Инновационного центра «Сколково», Института экономики РАН, Санкт-Петербургского Международного экономического форума.

Переход экономических процессов в цифровое пространство требует особого внимания $\mathrm{K}$ противоречиям интересов и стандартов управления информационно-цифровой системой. Россия тоже готова активно включиться в эту мировую гонку. И сейчас надо правильно выбрать ориентиры и критерии, чтобы пройти дорожную карту развития искусственного интеллекта в экономике Российской Федерации с максимальной эффективностью.

Учитывая особенности экономических связей Южной Осетии, которые носят суверенный характер и в финансово-хозяйственном плане зависимы от России, отметим, что практически все конъюнктурные изменения в России проецируются на Южную Осетию.

Руководство республики делает попытки изменения общей картины с цифровизацией, которая на сегодняшний день развита относительно слабо. О проектах, направленных на цифровизацию определённых секторов хозяйственной инфраструктуры РЮО, посвящены работы [4, 9].

В связи с этим разработка и реализация стратегии цифровой трансформации в контексте развития искусственного интеллекта в экономике Российской Федерации и цифровой экономики в Республике Южная Осетия особенно важны для создания концепции подготовки профессиональных кадров в условиях цифровой образовательной среды в образовательных учреждениях и координации действий организаторов и субъектов образования.

Maтериалы и методы / Materials and methods. Данное исследование является концептуально-теоретическим и базируется на изучении основ управления информационно-цифровой системой обеспечения единства образовательной и кадровой политик применительно к созданию возможностей ответа российского общества на большие вызовы научно-технологического развития страны в условиях цифровой экономики в контексте развития искусственного интеллекта.

При этом особое внимание уделяется расширению международных связей России и Южной Осетии, проблематике стимулирования инновационно-технологической активности территорий.

Методологической основой планируемого исследования послужат методы сравнительного анализа, системный и институциональный подходы, а также другие общенаучные методы и принципы познания.

Сочетание данных методов позволит установить потенциальные возможности и сильные стороны управления информационно-цифровой системой, направленные на общую реализацию инновационно-технологических задач развития стран.

Результаты и обсуждение / Results and discussion. Концептуальные основы управления информационно-цифровой системой обеспечения единства образовательной и кадровой политик территорий в контексте развития искусственного интеллекта в экономике Российской Федерации. Для роста конкуренции в экономическом развитии и наличия дополнительных преимуществ необходим учет значений цифровых и информационных технологий в управлении, поскольку наблюдается постоянное увеличение их уровня в современных организациях. От работников требуется хорошее образование. Человеческий капитал требует постоянного обновления (обучения), при этом он весьма чувствителен к способу обучения.

Сегодня важным видится решение задачи эффективного управления на основе единства образовательной и кадровой политик с использованием информационно-цифровых технологий путем:

- отслеживания текущего состояния рынка труда и образования в режиме реального времени и оперативного принятия решений о происходящих процессах;

- формирования постоянных систем связи бизнеса, профессиональных организаций, занимающихся подготовкой кадров, с целью формирования единой государственной политики в данном контексте; 
- создания методической системы, построенной на основе единства образовательной и кадровой политик в условиях многоуровневой информационно-цифровой образовательной среды и др.

С помощью применения информационных и цифровых технологий для развития системы управления рынком труда и образования можно строить планы сохранения и развития человеческого капитала, восстанавливать государственный контроль над этим процессом, имея прогнозные результаты развития предприятий, регионов и страны, а также оценивать результаты работы системы подготовки кадров. Человек должен свободно распоряжаться своим главным капиталом квалификацией. А для этого ему необходимо дать такую профессиональную подготовку, которая позволит легко освоить профессии в будущем, осознать возможность соб́ственного развития на основе информационных и цифровых технологий.

Проблемы не могут быть решены без привлечения к этой задаче самих работников, работодателей, общества в целом. Образование должно восприниматься обществом в истинном смысле, как место, где растят будущее страны, через которое развиваются информационные и цифровые технологии, модернизируется экономика, улучшается социально-экономическое состояние общества и государства [3]

К основным направлениям концептуальной реализации задачи эффективного управления информационно-цифровой системой обеспечения единства образовательной и кадровой политик территорий можно отнести:

- определение современных аспектов управления информационно-цифровой системой обеспечения единства образовательной и кадровой политик территорий,

- выявление технологии искусственного интеллекта как формы технологических решений, направленных на реализацию когнитивных функций человека, в контексте формирования цифровой экономики;

- разработка концепции управления информационно-цифровой системой обеспечения единства образовательной и кадровой политик территорий в контексте развития искусственного интеллекта в экономике Российской Федерации как ответ российского общества на большие вызовы научно-технологического развития страны, учитывающей мировой управленческий и технологический опыт, а также классификация и идентификация инструментов управления информационно-цифровой экономикой с точки зрения решения проблем научно-технологического развития.

Особенности развития цифровизации в Республике Южная Осетия. Поскольку в России уже принят ряд законодательных актов стратегического характера, нацеленных на цифровое развитие экономики, то с намеченным трендом развития экономики России ставится и вопрос перед экономикой Республики Южная Осетия о готовности идти в ногу со временем и постепенном переходе к цифровой экономике. Экономические связи Южная Осетия имеет только с Россией. Бюджет Республики в среднем на 90 \% дотируется Россией. Электроснабжение и газоснабжение также происходит из России. Таким образом, Республика Южная Осетия полностью в финансово-хозяйственном плане зависима от России.

При этом необходимо отметить, что цифровизация госуслуг в Южной Осетии находится в стадии становления. Например, в республике в сфере здравоохранения существует целый пласт проблем, основной из которых являются недостаток специалистов и оперативного доступа пациентов к врачам. И министерством здравоохранения на сегодня уже прорабатываются возможности создания телемедицины и интерактивной медицины с районами республики.

С октября 2018 г. в РЮО начало функционировать цифровое телевидение, которое охватило до $85 \%$ её территории. Планируется введение в республике в оборот карты платёжной системы «МИР». Денежные переводы за пределами РЮО возможно уже осуществлять через платёжную систему «Вконтакте» и «Золотая Корона». 
Достаточно широко распространён в РЮО и рынок интернет-закупок. Объясняется это более низкой стоимостью продукции в сравнении с ценами местных магазинов. В РЮО создан уже и свой сайт интернет-магазина.

Заказы товаров через Интернет преимущественно происходят через такие сайты, как: Aliexpress, Assos, Bershka, Zara, Lamoda, Mango, Otto, Ostin, Ozon, Wildberies и т. д. Объёмы заказов товаров в РЮО через Интернет определить весьма сложно, поскольку пункт доставки находится на территории России [7].

Таким образом, цифровизация в Республике Южная Осетия на сегодняшний день развита относительно слабо и нуждается в ряде проектов, направленных на определённые сектора хозяйственной инфраструктуры Республики.

Заключение / Conclusion. Человеческий капитал, являясь основным ресурсом цифровой экономики, требует применения новых подходов к управлению его развитием с учетом цифровых трендов в социально-экономических отношениях.

Решение задачи эффективного управления информационно-цифровой системой обеспечения единства образовательной и кадровой политик территорий в контексте развития искусственного интеллекта в экономике Российской Федерации и цифровой экономики в Республике Южная Осетия будет способствовать заметному технолого-экономическому росту страны в контексте стратегий на базе искусственного интеллекта в рамках ответа российского общества на большие вызовы научно-технологического развития Российской Федерации, а также позволит создать условия для развития международного научно-технологического сотрудничества России и Южной Осетии в формате дигитализации экономики.

\section{ЛИТЕРАТУРА И ИНТЕРНЕТ-РЕСУРСЫ}

1. Архипов, В. В. Интернет-право: учебник и практикум для бакалавриата и магистратуры / В. В. Архипов. - Москва : Юрайт, 2016. - Текст : непосредственный.

2. Вайпан, В. А. Основы правового регулирования цифровой экономики / В. А. Вайпан // Право и экономика. - 2017. - № 11. - С. 5-18. - Текст : непосредственный.

3. Григорьев, С. Г. Развитие человеческого капитала в условиях цифровизации / С. Г. Григорьев. В. В. Лукин, Д. В. Лукин // E-Management. - 2018. - № 2. - URL: https://cyberleninka.ru/article/n/razvitiechelovecheskogo-kapitala-v-usloviyah-tsifrovizatsii (дата обращения: 15.11.2019). - Текст : электронньй.

4. Кривицкий, В. О. Анализ эффективности экономической поддержки Российской Федерации, оказываемой Республике Южная Осетия / В. О. Кривицкий. - Москва : Изд-во «Горная книга», 2013. Текст : непосредственный.

5. Морхат, П. М. Искусственный интеллект: Правовой взгляд / П. М. Морхат. - Москва, 2017. - С. 51 . Текст : непосредственный.

6. Мочалин, А. Ю. Классификация систем с ИИ / А. Ю. Мочалин, Д. А. Назаров. - URL: www.vvsu.ru/ files/FCF9B6D0-B52F-4C9B-B144-8E8BC9354A51.pdf. - Текст : электронный.

7. О развитии цифровой экономики в PЮO. - URL: http://respublikarso.org/analytics/2424-o-razvitiicifrovoy-ekonomiki-v-ryuo.htm. - Текст : электронный.

8. Парахина, В. Н. О необходимости применения государственно-частного партнёрства в развитии цифровой экономики / В. Н. Парахина, Р. М. Устаев, О. А. Борис, Г. В. Воронцова, О. Н. Момотова // Вестник Северо-Кавказского федерального университета. - 2019. - № 2 (71). - Текст : непосредственный.

9. Тадтаев, Д. М. Современные ориентиры государственной инновационно-инвестиционной стратегии Республики Южная Осетия / Д. М. Тадтаев // Экономика и предпринимательство. - 2015. - № 10-2 (63). - С. 275-279. - Текст : непосредственный.

10. Тадтаев, Д. М. Формирование стратегии инновационно-инвестиционной политики в аспекте становления национальной экономики Респубблики Южная Осетия / Д. М. Тадтаев // Экономика и предпринимательство. - 2015. - № 9-2 (62). - С. 291-295. - Текст : непосредственный. 
11. Филипова, И. А. Искусственный интеллект и трудовые отношения: социальные перспективы и тенденции правового регулирования/ И. А. Филипова // Российская юстиция. -2017. - № 11. - С. 65-67. Текст : непосредственный

12. Parakhina, V. N. Human capital in digital economy: modern trends and innovative development opportunities/ V. N. Parakhina, R. M. Ustaev, E.I. Patrick, E. N. Novikova // The International Scientific and Practical Conference «Contemporary Issues of Economic Development of Russia: Challenges and Opportunities» The European Proceedings of Social \& Behavioural Sciences EpSBS. - 2018. - Pp. 793-802. - Текст : непосредственный.

\section{REFERENCES AND INTERNET RESOURCES}

1. Arkhipov, V. V. Internet-pravo: uchebnik i praktikum dlya bakalavriata i magistratury (Internet law: textbook and workshop for undergraduate and graduate studies) / V. V. Arkhipov. - Moskva : Yurait, 2016.

2. Vaipan V. A. Osnovy pravovogo regulirovaniya tsifrovoi ekonomiki (Fundamentals of legal regulation of the digital economy) / Vaipan V. A. // Pravo i ekonomika. - 2017. - № 11. - S. 5-18

3. Grigor'ev, S. G. Razvitie chelovecheskogo kapitala v usloviyakh tsifrovizatsii (Human capital development in the context of digitalization) / S. G. Grigor'ev, V. V. Lukin, D. V. Lukin // E-Management. - 2018. № 2. [Elektronnyi resurs]. - URL: https://cyberleninka.ru/article/n/razvitie-chelovecheskogo-kapitala-vusloviyah-tsifrovizatsii (data obrashcheniya: 15.11.2019)

4. Krivitskii, V. O. Analiz effektivnosti ekonomicheskoi podderzhki Rossiiskoi Federatsii, okazyvaemoi Respublike Yuzhnaya Osetiya (Analysis of the effectiveness of economic support of the Russian Federation to the Republic of South Ossetia) / V. O. Krivitskii. - Moskva : Izd-vo «Gornaya kniga», 2013.

5. Morkhat, P. M. Iskusstvennyi intellekt: Pravovoi vzglyad (Artificial intelligence: a Legal view) / P. M. Morkhat. - Moskva, 2017. - S. 51.

6. Mochalin, A. Yu. Klassifikatsiya sistem s II (Classification of artificial intelligence systems) / A. Yu. Mochalin, D. A. Nazarov [Elektronnyi resurs]. - URL: www.vvsu.ru/files/FCF9B6D0-B52F-4C9B-B1448E8BC9354A51.pdf

7. O razvitii tsifrovoi ekonomiki v RYuO (On the development of the digital economy in the Republic of South Ossetia) [Elektronnyi resurs]. - URL: http://respublikarso.org/analytics/2424-o-razvitii-cifrovoyekonomiki-v-ryuo.html

8. Parakhina, V. N. O neobkhodimosti primeneniya gosudarstvenno-chastnogo partnerstva v razvitii tsifrovoi ekonomiki (On the need for public-private partnership in the development of the digital economy) / V. N. Parakhina, R. M. Ustaev, O. A. Boris, G. V. Vorontsova, O. N. Momotova // Vestnik SeveroKavkazskogo federal'nogo universiteta. - 2019. - № 2 (71).

9. Tadtaev D. M. Sovremennye orientiry gosudarstvennoi innovatsionno-investitsionnoi strategii Respubliki Yuzhnaya Osetiya (Modern guidelines of the state innovation and investment strategy of the Republic of South Ossetia) / D. M. Tadtaev // Ekonomika i predprinimatel'stvo. - 2015. - № 10-2 (63). - S. 275-279.

10. Tadtaev, D. M. Formirovanie strategii innovatsionno-investitsionnoi politiki $\mathrm{v}$ aspekte stanovleniya natsional'noi ekonomiki Respubliki Yuzhnaya Osetiya (Formation of the strategy of innovation and investment policy in the aspect of the formation of the national economy of the Republic of South Ossetia) / D. M. Tadtaev // Ekonomika i predprinimatel'stvo. - 2015. - № 9-2 (62). - S. 291-295

11. Filipova, I. A. Iskusstvennyi intellekt i trudovye otnosheniya: sotsial'nye perspektivy i tendentsii pravovogo regulirovaniya (Artificial intelligence and labor relations: social perspectives and trends of legal regulation) / I. A. Filipova // Rossiiskaya yustitsiya. - 2017. - № 11. - S. 65-67.

12. Parakhina, V. N. Human capital in digital economy: modern trends and innovative development opportunities/ V. N. Parakhina, R. M. Ustaev, E.I. Patrick, E. N. Novikova // The International Scientific and Practical Conference «Contemporary Issues of Economic Development of Russia: Challenges and Opportunities» The European Proceedings of Social \& Behavioural Sciences EpSBS. - 2018. - Pp. 793-802.

\section{СВЕДЕНИЯ ОБ АВТОРАХ}

Устаев Рустам Мерзеферович, кандидат экономических наук, доцент кафедры менеджмента Института экономики и управления ФГАОУ ВО «Северо-Кавказский федеральный университет», г. Ставрополь.E-mail:110213rabota@mail.ru 
Гюльнезерова Мальвина Нережсллаховна, аспирант кафедры менеджмента Института экономики и управления ФГАОУ ВО «Северо-Кавказский федеральный университет», г. Ставрополь. E-mail: naukamanagement $(a$ mail.ru

Tадmaев Дзамболат Мервадикович, кандидат экономических наук, доцент кафедры экономики и предпринимательства Инженерно-экономического факультета Юго-осетинского государственного университета имени А. А. Тибилова, Республика Южная Осетия. E-mail:: tadtaev_dm(a)mail.ru

\section{INFORMATION ABOUT AUTHORS}

Rustam Ustaev, Candidate of Economic Sciences, associate Professor of the Department of Management, Institute of Economics and Management, North-Caucasian Federal University, Stavropol. E-mail:110213rabota@ mail.ru

Mal'vina Gyul'nezerova, graduate student, Department of Management, Institute of Economics and Management. North-Caucasian Federal University, Stavropol. E-mail: naukamanagement $a$ mail.ru

Dzambolat Tadtaev, Candidate of Economic Sciences, Associate Professor, Department of Economics and Entrepreneurship, Faculty of Engineering and Economics, South Ossetian State University named after A. A. Tibilov, Republic of South Ossetia. E-mail: tadtaev_dm@mail.ru 